\title{
Alternative final steps in berberine biosynthesis in Coptis japonica cell cultures
}

\author{
E. Galneder ${ }^{1}$, M.Rueffer ${ }^{1}$, G. Wanner ${ }^{1,2}$, M. Tabata ${ }^{1,3}{ }^{3}$, and M. H. Zenk ${ }^{1}$ \\ ${ }^{1}$ Lehrstuhl für Pharmazeutische Biologie der Universität München, Karlstrasse 29, D-8000 München 2, Federal Republic of Germany \\ 2 Botanisches Institut der Universität München, Menzinger Strasse 67, D-8000 München 19, Federal Republic of Germany \\ 3 Faculty of Pharmaceutical Sciences, Kyoto University, Kyoto 606, Japan
}

Received October 30, 1987 - Communicated by K. Hahlbrock

\section{ABSTRACT}

In Coptis japonica cell cultures an alternative pathway has been discovered which leads from (S)-tetrahydrocolumbamine via (S)-canadine to berberine. The two enzymes involved have been partially purified. (S)-Tetrahydrocolumbamine is stereospecifically transformed into (S)-canadine under formation of the methylenedioxy bridge in ring $A$. This new enzyme was named (S)-canadine synthase. (S)-Canadine in turn is stereospecifically dehydrogenated to berberine by an oxidase, (S)-canadine oxidase (COX), which was partially purified (25-fold). This enzyme has many physical properties in common with the already known (S)-tetrahydroprotoberberine oxidase from Berberis but grossly differs from the latter enzyme in its cofactor requirement ( $\mathrm{Fe}$ ) and its substrate specificity. Neither (S)-norreticuline nor (S)-scoulerine serves as substrate for the coptis enzyme, while both substrates are readily oxidized by the Berberis enzyme. The four terminal enzymes catalyzing the pathway from (S)-reticuline to berberine are housed in Berberis as well as in coptis in smooth vesicles with a density of $\rho=1.14 \mathrm{~g} / \mathrm{ml}$. These vesicles have been enriched and characterized by electron microscopy.

\section{INTRODUCTION}

Berberine is the first plant alkaloid whose biosynthesis is completely known at the enzyme level (Zenk et al., 1985). Recently the early steps in the pathway leading from tyrosine to reticuline, the universal precursor for isoquinoline alkaloids, had to be revised (Stadler et al., 1987) in that norcoclaurine was recognized as the first alkaloid intermediate in reticuline biosynthesis (Loeffler et al., 1987). The berberine pathway has been worked out mainly using cell cultures of different Berberis species as the experimental material. Cell suspension cultures of coptis japonica, on the other hand, have been optimized to such a degree that the commercial production of berberine seems now feasable (see Fujita and Tabata, 1987). In order to understand the alkaloid biosynthes is at the biochemical and cytological level in this tissue we set out to compare the pathway for berberine formation in Coptis with the established pathway in our Berberis system. This study was justified due to the report of Yamada and okada (1985) on a crude enzyme from Coptis which converted $(S)$-tetrahydroberberine $(=(S)$-canadine) to berberine. This unpurified enzyme was strikingly different from the (S)-tetrahydroprotoberberine oxidase (STOX) reported from our laboratory (Amann et al., 1984) in that the coptis enzyme dehydrogenated only (S)-canadine while other tetrahydroprotoberberines were reported to be inactive. In further contrast to the STox enzyme, their enzyme did not produce hydrogen peroxide but rather $\mathrm{H}_{2} \mathrm{O}$ as one of the reaction products. Our analysis of the coptis system reported here led to the surprising result that the terminal two steps in the biosynthesis of berberine in Berberis and Coptis are biochemically completely different while similar at the cytological level.

\section{MATERIAL and METHODS}

CELL CULTURES - B. stolonifera was cultivated in Linsmaier and Skoog (1965) medium as previously described (Amann et al., 1986), and C. japonica under conditions as given by Fukui et al. (1982).

ENZYME PREPARATION - Cells of $c$. japonica were harvested after 10 days of cultivation and frozen in liquid nitrogen. Typically $100 \mathrm{~g}$ fresh weight were thawed while stirring in $200 \mathrm{ml} 10 \mathrm{mM}$ phosphate buffer ( $\mathrm{pH} 7.5,5 \mathrm{mM}$ B-mercaptoethanol). After $30 \mathrm{~min}$ the mass was pressed through cheese-cloth and centrifuged for $10 \mathrm{~min}$ at $13500 \mathrm{x} \mathrm{g}$. The clear supernatant was applied to an XAD-2 column (XAD-2, $0.31-1 \mathrm{~mm}$, Serva Heidelberg, column: $2.5 \times 15 \mathrm{~cm}$, flow rate: $100 \mathrm{ml} / \mathrm{h})$, equilibrated with $10 \mathrm{mM}$ phosphate buffer ( $\mathrm{pH} 7.5,5 \mathrm{mM}$ B-mercapotethanol). The eluate of the column $(230 \mathrm{ml})$ was applied to a DEAESephacel column (Pharmacia, $2.5 \times 18 \mathrm{~cm}$, flow rate $35 \mathrm{ml} / \mathrm{h}$ ) equilibrated with the buffer described above. The protein was eluted with a linear gradient of $\mathrm{KCl}(0-1 \mathrm{M} \mathrm{KCl}, 8 \mathrm{~h})$ in fractions of $5 \mathrm{ml}$. The oxidase was detected in fractions $125-142$ (92 ml) which were pooled and dialyzed against $10 \mathrm{mM}$ phosphate buffer ( $\mathrm{pH} 7.5,5 \mathrm{mM}$ ß-mercaptoethanol). The dialyzed enzyme solution was applied to a QAE-column (QAE fast flow, FPLC-system Pharmacia, $1.0 \times 10 \mathrm{~cm}$ ) at a flow rate of $1 \mathrm{ml} / \mathrm{min}$ equilibrated with the standard phosphate buffer. The enzyme was eluted with a linear gradient from $0-0.3 \mathrm{M} \mathrm{KCl}$ (70 min, flow rate: $1 \mathrm{ml} / \mathrm{min}$ ) in $1 \mathrm{ml}$ fractions. The enzyme was detected in fractions $44-64(20 \mathrm{ml})$, pooled and dialyzed again against the standard buffer. The resulting protein solution was bound to a red $A$ column (Procion red (Ciba-Geigy) bound to TSK-gel (Merck)) at a flow rate of $15 \mathrm{ml} / \mathrm{h}$ (column: $1.5 \times 30$ $\mathrm{cm}$, equilibrated with standard buffer). The protein was incubated on the column for $2 \mathrm{~h}$ and afterwards the enzyme could be eluted with the equilibration 
buffer ( $36 \mathrm{ml}$ ), about a 25-fold purification resulted with a specific activity of $6.5 \mathrm{pkat} / \mathrm{mg}$. The molecular weights of the enzymes were determined by gel filtration HPLC (G-3000 SW, LKB, $21.5 \times 600 \mathrm{~mm})$. The isoelectric point was determined by preparative isoelectric focusing in a granulated flat agarose gel from $\mathrm{pH} 4.5-6.0$ (LKB). Protein determinations were performed according to Bradford (1976).

ENZYME ASSAYS - The reaction mixture $(250 \mu l)$ included 25 umoles borate buffer (pH 8.9), 1 nmole (R,S)-[8,14-tritium]-canadine $(20000 \mathrm{cpm})$ and enzyme (up to $300 \mu \mathrm{g}$ protein). The assay mixture was incubated for $20 \mathrm{~min}$ at $30^{\circ} \mathrm{C}$ and the reaction terminated by addition of $300 \mu \mathrm{l}$ dextran coated charcoal $(1 \mathrm{~g} / 10 \mathrm{ml})$. The suspension was centrifuged for $5 \mathrm{~min}$ in an Eppendorf centrifuge and an aliquot of $250 \mu \mathrm{l}$ removed for scintillation counting (Rotiszint 22, Roth). The optical assay was performed using the stereochemically pure isoquinoline alkaloids according to Amann et al. (1986). (S)-Canadine synthase was assayed as stated previously (Rueffer and Zenk, 1985), however, using (R,S)-[3-methoxy-tritium]tetrahydrocolumbamine.

VESICLE ISOLATION AND ELECTRON MICROSCOPY - The vesicles were isolated by isopycnic sucrose density gradient centrifugation and characterized by electron microscopy according to Amann et al. (1986). Atomic absorption spectroscopy (graphite column mode) was performed on a Perkin Elmer 1100B instrument.

\section{RESULTS}

ENZYMOLOGY OF BERBERINE FORMATION - C. japonica cells grown under conditions of high berberine production were used as an enzyme source. Crude protein extracts were analyzed for their ability to oxidize a variety of tetrahydroprotoberberines. Using the very sensitive tritium removal assay as well as the optical assay it could be shown that (S)-canadine was by far the best substrate (100\%) followed by (S)-scoulerine $(16 \%),(R, S)$-tetrahydrojatrorrhizine $(15 \%),(R, S)-$ coreximine $(7 \%)$, (R,S)-stylopine and (R,S)-tetrahydrocolumbamine (each $6 \%$ ), and by $(R, S)$-tetrahydropalmatine $(5 \%)$. Tetrahydroprotoberberines with $(R)$ configuration were not utilized as substrates. The presence of various protoberberines in this crude and colored protein extract may have influenced the oxidase activity in a negative way and the results have to be interpreted more in a qualitative manner. Regardless of this potential interference, the experiment demonstrates the presence of oxidase activity similar to the one previously observed in Berberis. There was, however, one major difference in the substrate specificity. While the Berberis oxidase catalyzes the dehydrogenation of (S)-norreticuline with high activity to 1,2-dehydronorreticuline (Amann et al., 1987), the Coptis enzyme clearly did not transform this substrate. This behaviour as well as the observations of Yamada and Okada (1985) made it likely that the coptis oxidase was different from the Berberis enzyme. In order to investigate this hypothesis we set out to purify this enzyme. In a three step procedure the canadine dehydrogenating enzyme from coptis could be purified about 25 -fold. One major obstacle in purifying the enzyme was its lability. The enzyme has a half life of about 2 days in dilute solution. During the purification procedure it was noticed that the enzyme exists in two forms, a high molecular form (ca. $150 \mathrm{kD}$ ) and a low one (ca. $58 \mathrm{kD})$. Both enzyme activities were isolated and tested for their substrate specificities. As shown in Table 1 , both enzyme forms catalyzed exclusively the oxidation of (S)-canadine and not of (R)-canadine. Stylopine and tetrahydrocolumbamine were dehydrogenated as well, while scoulerine and norreticul ine were not. The $58 \mathrm{kD}$ enzyme which was present in the cells predominantly (ca. 60\%) was further characterized and compared to the enzyme from Berberis wilsoniae.

\begin{tabular}{|c|c|c|}
\hline Substrate & $\begin{array}{l}\text { Enzyme } \\
155 \mathrm{kD}\end{array}$ & $\begin{array}{r}\text { activity in \% } \\
58 \mathrm{kD}\end{array}$ \\
\hline (S)-Canadine & 100 & 100 \\
\hline (R)-Canadine & 0 & 0 \\
\hline$(R, S)$-Stylopine & 11 & 26 \\
\hline$(R, S)$-Tetrahydrocol umbamine & 5 & 5 \\
\hline$(R, S)$-scoulerine & 0 & 0 \\
\hline$(\mathrm{R}, \mathrm{S})$-Norreticuline & 0 & 0 \\
\hline
\end{tabular}

Table 1 Substrate specificity of the high and low molecular weight forms of Coptis (S)-canadine oxidase. The assay conditions were given in material and methods.

Both enzymes are very similar; in their physical properties they show the same $\mathrm{pH}$ (Berberis: $\mathrm{pH}$ 8.9, Coptis: $\mathrm{pH} 8.7)$ and temperature optimum $\left(40^{\circ} \mathrm{C}\right)$, they both occur in a higher and lower $M_{\tau}$ form, they have similar isoelectric points ( $\mathrm{pH} 5.7 / \mathrm{pH} \mathrm{5.3),} \mathrm{they}$ catalyze the dehydrogenation of only the (S)-forms of their substrates, they both exist in specific vesicles (see below), and the products of the reaction are the quaternary protoberberine and hydrogen peroxide. One difference is, however, while the oxidase from Berberis is a flavin enzyme (Amann et al., 1984), the Coptis enzyme clearly contains iron as shown by atomic absorption spectroscopy of the electrophoretically pure enzyme and by its inhibition by orthophenanthroline ( $50 \%$ inhibition at $0.05 \mathrm{mM}$ ), a behaviour which is not shown by the Berberis enzyme. The major difference, however, is seen in the substrate specificity of both enzymes. While the Berberis enzyme is fully active towards (S)-scoulerine, (S)canadine and (S)-norreticuline, the coptis enzyme catalyzes only the oxidation of (S)-canadine. We therefore propose to call this enzyme (S)-canadine oxidase (COX) or (S)-tetrahydroberberine oxidase (Yamada and Okada, 1985), in contrast to the Berberis enzyme which we have termed (S)-tetrahydroprotoberberine oxidase (STOX) because of its much wider substrate range.

Having now established that (S)-canadine is the preferred substrate for the coptis oxidase catalyzing the last step in berberine formation, the question arises at which stage of biosynthetic events is the methylenedioxy group present in berberine formation. It has been established beyond any doubt that in the Berberis system the introduction of the methylenedioxy group occurs at the quaternary alkaloid level and columbamine is transformed into berberine by action of berberine synthase as a last step in its biosynthesis (Rueffer and Zenk, 1985). Due to the substrate specificity of the oxidase (cox) the coptis enzyme introducing the methylenedioxy group must act on the corresponding tetrahydroprotoberberine, namely (s)-tetrahydrocolumbamine, thus forming (S)-canadine. It has been previously known that the terminal steps of berberine biosynthesis are located exclusively in specific vesicles contained in the cells of protoberberine containing plants (Amann et al., 1986), none of these enzymes are present in the cytosol. Therefore vesicles were isolated from both Berberis stolonifera as well as from Coptis japonica employing the method of Amann et al. (1986). Incubation of the 
enzyme with columbamine after breaking the vesicle membranes by brief freezing and thawing showed in the case of Berberis that this was the substrate for the methylenedioxy bridge-forming berberine synthase (20.1 pkat/mg protein). Columbamine, however, was absolutely not transformed by the coptis vesicular enzyme. Coptis, however, transformed with equal efficacy tetrahydrocolumbamine to canadine (24.6 pkat/mg protein). This new enzyme which is contained in the coptis vesicles catalyzes a new reaction in that the methylenedioxy bridge is introduced at the tertiary, tetrahydro stage. We name this enzyme (S)canadine synthase. Since in the case of Berberis the four terminal enzymes involved in berberine biosynthesis, the berberine bridge enzyme, scoulerine-90 -methyltransferase, as well as STOX and berberine synthase are located in specific vesicles (Zenk et al., 1985), we investigated whether this is also the case with Coptis. Vesicles were isolated from B. stolonifera and from $C$. japonica and all four enzymes analyzed in these preparations. As demonstrated in Fig. 1, both in Berberis and Coptis vesicles are present which have a density of $\rho=1.14 \mathrm{~g} / \mathrm{ml}$, as determined by sucrose density gradient centrifugation. These vesicles isolated from both species contain in each case the four terminal enzymes transforming (S)-reticuline to berberine.
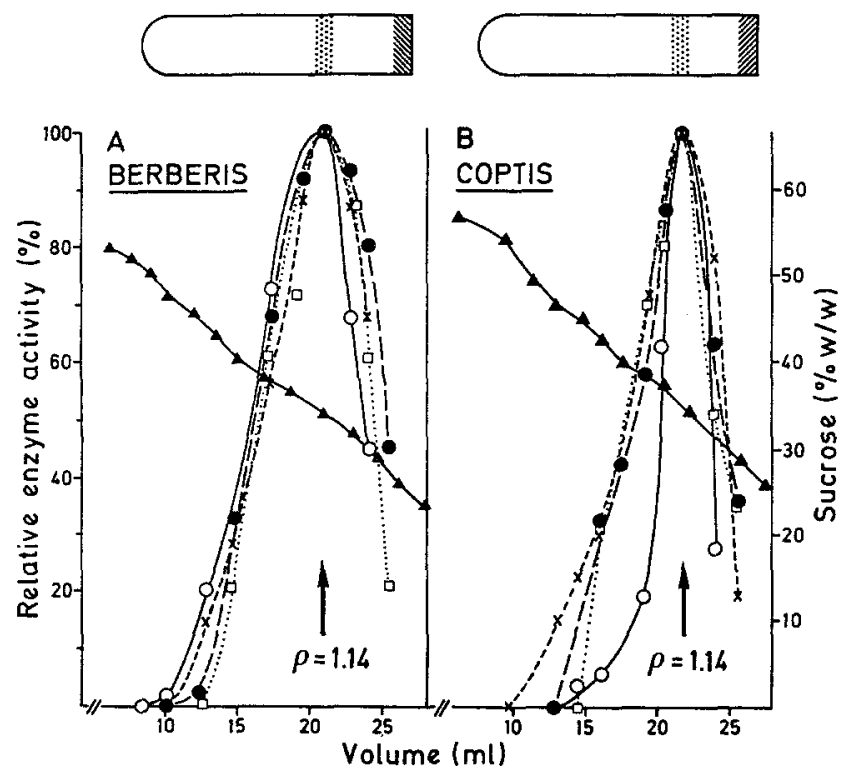

Fig. 1 Typical fractionation profile of a sucrose density gradient separation of vesicles isolated from A. Berberis: Berberine bridge enzyme (-- $)$; (S)-scoulerine-9-0methylt ransferase ( $\square \cdot \square) ;(S)$-t et rahydroprotoberberine oxidase $(x--x)$; berberine synthase $(0-0)$; sucrose concent ration $(\mathbf{\Lambda}-\mathbf{\Lambda})$. B. Coptis: Berberine bridge enzyme ( $\bullet--\bullet)$; (S)-scoulerine-9-0-methylt ransferase $(\square . . \square)$; (S)-canadine synthase $(\mathrm{o}-\mathrm{o}) ;(\mathrm{S})$-canadine oxidase $(\mathrm{x}-\mathrm{-x})$; sucrose concent ration $(\mathbf{\Lambda}-\mathbf{\Lambda})$.

Vesicles from Berberis as well as from coptis contain the berberine bridge enzyme, thus catalyzing the formation of (S)-scoulerine from (S)-reticul ine. The (R)-enantiomer of reticuline is not used as substrate in either system. Also present in both vesicular bands is the SAM: (S)-scoulerine-9-0-methyltransferase, yielding (S)-tetrahydrocol umbamine from (S)scoulerine. Therefore, in both plant species these two steps leading from (S)-reticuline to (s)-tetrahydrocolumbamine are the same. After this intermediate, the pathways diverge. While in Berberis tetrahydrocolumbamine is first oxidized and then the methylenedioxy bridge introduced, in coptis the methylenedioxy forming enzyme acts on the tetrahydroprotoberberine first to yield (S)-canadine which is subsequently oxidized to the final product of both pathways, berberine.

It has previously been found by electron microscopic observation (Yamamoto et al., 1986) that berberine producing strains of $c$. japonica contain an abundance of cytoplasmic vesicles $0.5-1 \mu \mathrm{m}$ in diameter. These vesicles are obviously similar or identical with those vesicles isolated from Berberis and three other alkaloid containing members of different plant families which have been shown to contain exclusively all the enzymes necessary for protoberberine formation (Amann et al., 1986). We therefore attempted here a direct comparison of the functionally characterized vesicles (see above) of $\mathbf{C}$. japonica with those isolated from B. stolonifera both of which have a density of $\rho=1.14 \mathrm{~g} / \mathrm{ml}$. Electron micrographs of the vesicle fraction are shown in Fig. 2 .

As can be seen, there is an abundance of vesicles 0.1 - 1 um in diameter which make up this vesicular band. They undoubtedly contain the enzymes for protoberberine synthesis. As has been observed previously for Berberis (Amann et al., 1986), the Coptis vesicles are also yellow in color and chromatographic analys is shows that they contain berberine, coptisine, palmatine, and jatrorrhizine in the same ratio as found in vacuoles (data not shown). This indicates that the vesicles are the origin of synthesis of protoberberines and are also involved in the transport of these quaternary alkaloids.

\section{DISCUSSION}

The pathway to berberine had been previously completely worked out at the enzyme level using mainly Berberis cell cultures (Zenk et al., 1985). The main feature of the Berberis pathway is the 5-step formation of (S)-reticul ine from dopamine and 4hydroxyphenylacetaldehyde and the subsequent entrance of this central intermediate into a smooth vesicle. (s)-Reticuline, having entered this compartment, is immediately transformed to (S)-scoulerine which is subsequently methylated at the 9-0-position to yield (S)-tetrahydrocolumbamine. This intermediate in Berberis is first oxidized by STOX to columbamine and subsequently in a final step the methylenedioxy group is formed at the level of the quaternary protoberberine to result in berberine. This route, as can be judged from the catalytic properties of the STOX enzyme, is realized in the plant families Berberidaceae, Papaveraceae, and Menispermaceae. It seems to be therefore the main pathway in the plant kingdom. In this paper, however, we present an alternative route to berberine which corresponds to a previously postulated but experimentally, at the enzyme level, not proven pathway (Barton et al., 1965). Yamada and Okada (1985) have made the important observation that in crude extracts of $\mathbf{C}$. japonica an oxidase is found which is in its properties different from the previously described STOX enzyme (Amann et al., 1984): the Coptis enzyme dehydrogenates exclusively (S)-canadine and in contrast to the Berberis oxidase does not yield hydrogen peroxide but water. Indeed, we confirm in this paper that the Coptis oxidase is different from the Berberis oxidase. However, the original observations on the coptis oxidase have to be modified. First, in the crude coptis extract there are several oxidases acting on tetrahydroprotoberberines. The main oxidase described in this paper was shown to dehydrogenate mainly (S)-canadine, but in contrast to previous assumption, also acted on other (S)-tetrahydroprotoberberines such as stylopine and tetrahydrocolumbamine. The main difference between the coptis and the Berberis oxidase is, however, that 

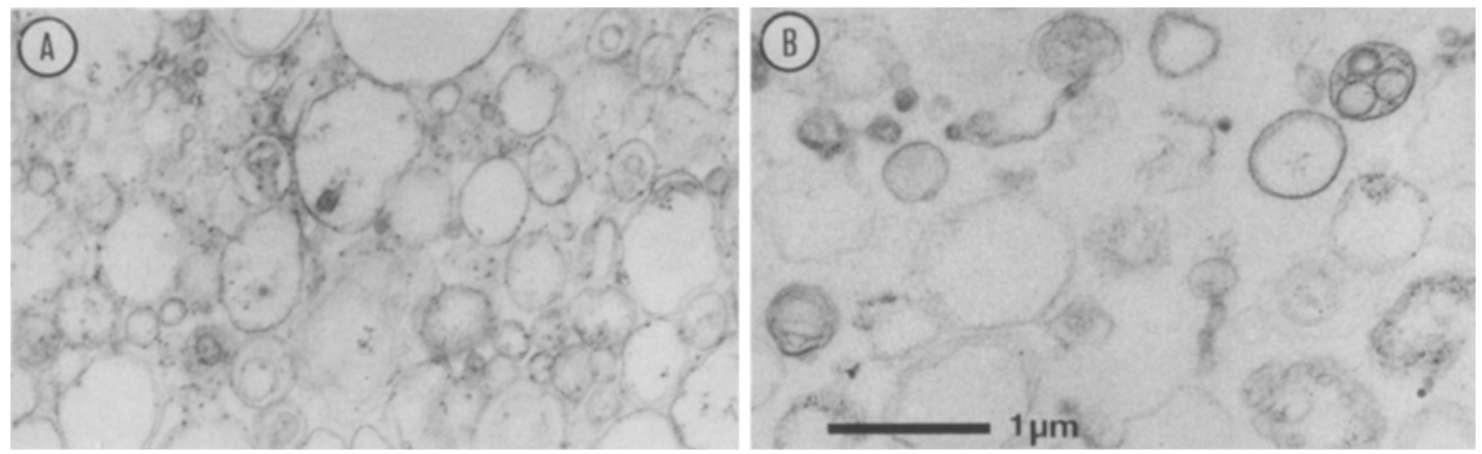

Fig. 2 Electron micrographs of ultra thin sections of the particulate fraction after sucrose density gradient centrifugation. This fraction is predominantly composed of vesicles with a diameter ranging from 0.1 to $1.0 \mu \mathrm{m}$. A. Coptis; B. Berberis.

the latter oxidizes with high efficiency norreticuline and scoulerine. Both enzymes produce as one of the reaction products hydrogen peroxide. This fact was missed by Yamada and Okada (1985), since these authors used crude enzyme extracts from coptis probably containing catalase, which degraded the reaction product. Both enzyme systems are housed in smooth vesicles which are the site of synthesis of protoberberines and also seem to be the carriers to transport these quaternary alkaloids to the vacuoles, the final storage compartment. In spite of this and the physical similarities of both enzymes as shown in Fig. 2, the final steps of berberine biosynthesis in the Berberis and the Coptis system are fundamental iy different as shown in Fig. 3 .

The fact that there are two alternative pathways for one and the same secondary plant product should serve as a warning to us not to generalize pathways even if this metabolic route is completely established at the enzyme level for one species. This fact will increase the number of biotechnologically interesting enzymes involved in secondary metabolism in plants, over the enormous number already expected by assuming that each product is formed only by one and the same pathway.

ACKNOWLEDGEMENT - This work was supported by Sonderforschungsbereich 145 of Deutsche Forschungsgemeinschaft, Bonn, and Fonds der Chemischen Industrie. We thank Dr. T. M. Kutchan for her linguistic help in the preparation of this manuscript and Miss S. Kunz for excellent technical assistance.

\section{REFERENCES}

Amann M, Nagakura N, Zenk MH (1984) Tetrahedron Lett. 25: 953-954

Amann M, Wanner G, Zenk MH (1986) Planta 167: $310-320$

Amann M, Nagakura N, Zenk MH (1987) Phytochem., in press

Barton DHR, Hesse RH, Kirby GW (1965) J. Chem. Soc. 6379

Bradford MM (1976) Anal. Biochem. 72: 248-254

Fujita Y, Tabata M (1987) In: Green CE, Somers DA, Hackett WP, Biesboer DD (eds) Plant tissue and cell culture. Alan R Liss Inc, New York, 169-186

Fukui H, Nakagawa K, Tsuda S, Tabata M (1982) In: Fujiwara A (ed) Plant Tissue Culture 1982, Maruzen, Tokyo, pp 313-314

Linsmaier EM, Skoog F (1965) Physiol. Plant. 18: 100-127

Loeffler S, Stadler R, Nagakura N, Zenk MH (1987) J. Chem. Soc., Chem. Commun.: 1160-1162

Rueffer M, Zenk MH (1985) Tetrahedron Lett. 26: 201-202

Stadler R, Kutchan TM, Loeffler S, Nagakura N, Cassels B, Zenk MH (1987) Tetrahedron Lett. 28: $1251-1252$

Yamada $Y$, Okada $N$ (1985) Phytochem. 24: 63-65

Yamamoto $H$, Nakagawa K, Fukui H, Tabata M (1986) Plant Cell Reports 5: 65-68

Zenk MH, Rueffer $M$, Amann $M$, Deus-Neumann B, Nagakura N (1985) J. Nat. Products 48: 725-738

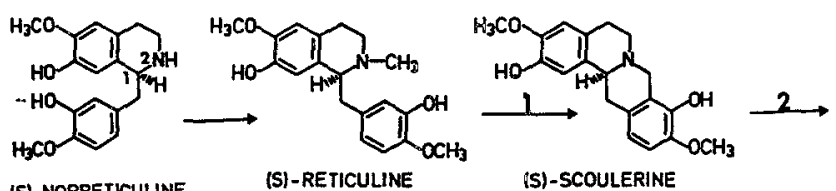

(S)-NORRETICULINE

(S)-RETICULINE<smiles>COc1cc2c(cc1O)CCc1cc(OC)c(OC)cc1C2</smiles>

COLUMBAMINE

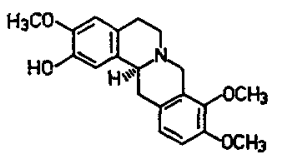

(5)-TetraHYdRocolumbamine S5
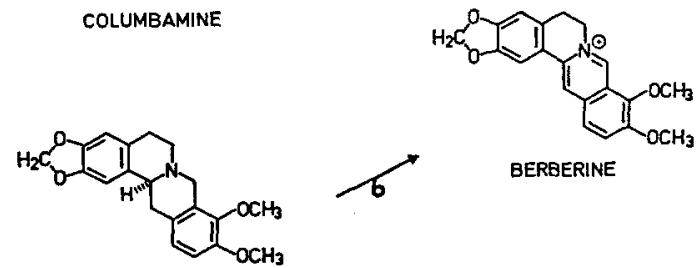

BERBERINE
Fig. 3 Biosynthetic sequence leading from (S)-reticuline to berberine catalysed by two common enzymes: 1. berberine bridge enzyme, 2 . ( $S$ )scoulerine-9-0-methylt ransferase, and two enzymes specific for the Berberis pathway: 3. (S)-tet rahydroprotoberberine oxidase and 4 . berberine synthase. The alternative Coptis pathway is characterized by 5 . (S)-canadine synthase and 6. (S)-canadine oxidase. 